features of megamitochondria. Focal lobular inflammation was seen associated with spotty necrosis in one focus. HG arises from disruption of the normal balance between glycogenesis and glycogenolysis, leading to trapping of glycogen within the hepatocytes. This leads to hepatomegaly and consequent liver damage which becomes evident with blood release of aminotransferases.

\section{IDENTIFICATION OF POTENTIALLY MISLEADING TERMINOLOGY IN THE FIVE CURRENTLY PUBLISHED FIFTH EDITION WHO CLASSIFICATION OF TUMOURS: AN UPDATE}

$\underline{\text { Zi Long Chow }}^{1,2}$, Valerie A. White ${ }^{3}$, Bianca Iciar Indave ${ }^{3}$, Menaka Dilani Samarawickrema Lokuhetty ${ }^{3}$, Ian A. Cree ${ }^{3}$ ${ }^{1}$ Launceston General Hospital, Tasmania, Tas, Australia; ${ }^{2}$ University of Tasmania, Tasmania, Tas, Australia; and ${ }^{3}$ WHO Classification of Tumours Program, International Agency for Research on Cancer, Lyon, France

Aim: To describe the frequency of use of a set of potentially misleading terms in the WHO Classification of Tumours, 5th Edition Blue Books (BB).

Methods: We used 26 previously identified potentially misleading pathology-related terms ${ }^{1}$ that lack definitional support and performed a second phase descriptive study to report the frequency of use within the 5th edition BB.

Results: The 26 misleading terms were utilised a total of 6450 times in all books: 1477 times in Digestive System Tumours (DST), 574 times in Breast Tumours (BT), 1119 times in Female Genital Tract (FGT), 1899 times in Soft tissue and Bone Tumours (STB) and 1381 times in Thoracic Tumours (TT). In all BB, the suffix 'oid' was the most frequently observed term. Other common terms included '-like', 'epithelioid', 'pseudo', 'dysplasia', 'carcinoid', and 'microinvasion and microinvasive'. In STB, TT and BT, the majority of potentially misleading terms were located in one chapter. FGT and DST showed a more even distribution across chapters.

Conclusion: We detected frequent use of potentially misleading terminology in the WHO Classification of Tumours BB, 5th series. A contextual analysis of the linguistic use is planned to determine possible alternative terminology.

\section{Reference}

1. Chow ZL, Indave BI, Lokuhetty MDS, et al. Misleading terminology in pathology: lack of definitions hampers communication. Virchows Arch 2021; Apr 2: 10.1007/s00428-02103069-7.

\section{SCLEROSING PNEUMOCYTOMA - A CASE REPORT}

Anita Chu, Jeremy Hyde

Canterbury Health Laboratories, Christchurch, New Zealand

Sclerosing pneumocytoma is a benign but rare neoplasm of the lungs, usually incidentally found, and with a striking female predilection. Microscopically the key feature of these neoplasms is the presence of two cell populations: surface cuboidal cells and stromal round cells, arranged as papillary, sclerosing, solid and haemorrhagic patterns in variable proportions.

We present a case report of a Caucasian female in her 30s who presented with an incidentally discovered, slowly enlarging mass in the right upper lung lobe. A subsequent lobectomy was performed and the mass was found to be a sclerosing pneumocytoma.

This case highlights the typical histologic and immunohistochemical features of sclerosing pneumocytoma.

\section{UNUSUAL CLINICAL PRESENTATION OF A CROOKE CELL ADENOMA - A RARE AND AGGRESSIVE PITUITARY ADENOMA VARIANT}

Kimberley Chung ${ }^{1}$, Jason Dyke ${ }^{1,2}$, Alexandra Kang ${ }^{1,3}$

${ }^{1}$ Department of Neuropathology, PathWest, Royal Perth Hospital, Perth, WA, Australia; ${ }^{2}$ University of Western Australia, Perth, WA, Australia; and ${ }^{3}$ University of Notre Dame, Perth, WA, Australia

Pituitary adenomas are common intracranial neoplasms, making up approximately $15 \%$ of all intracranial tumours. ${ }^{1}$ The clinically non-functioning pituitary adenomas that show hormonal or transcription factor production on immunohistochemistry are termed 'silent'. Crooke cell adenoma (CCA) is one of the recently defined high-risk pituitary adenoma subtypes and comprises $4 \%$ of corticotroph adenomas. ${ }^{2}$ Most patients with CCAs present with Cushing's disease, however, there are rare cases of silent CCAs reported in the literature.

We present a case of silent CCA in a 65-year-old female who presented with headache and vertigo. Histopathology of the resected macroadenoma showed characteristic immunohistochemical and ultrastructural findings. Pathologists should be aware of the diagnostic criteria for CCA regardless of the tumour's functional status due to the high recurrence rates of CCA after transsphenoidal resection. ${ }^{3}$

References

1. Drummond J, Roncaroli F, Grossman AB, et al. Clinical and pathological aspects of silent pituitary adenomas. J Clin Endocrinol Metab 2019; 104: 2473-89.

2. Lloyd RV, Osamura RY, Klöppel G, et al., editors. WHO Classification of Tumours of Endocrine Organs. 4th ed. Lyon: IARC, 2017.

3. George D, Scheithauer B, Kovacs K, et al. Crooke's cell adenoma of the pituitary: an aggressive variant of corticotroph adenoma. Am J Surg Pathol 2003; 27: 1330-6.

\section{EFFICACY OF TRAINING A DEEP LEARNING MODEL FOR MITOTIC COUNT IN BREAST CARCINOMA USING OPENSOURCE SOFTWARE}

Nathan Clarke ${ }^{1}$, Andrew Dettrick ${ }^{1,2}$, Jane Armes ${ }^{2}$

${ }^{1}$ School of Medicine and Dentistry, Griffith University, Southport, Qld, Australia; and ${ }^{2}$ Pathology Queensland, Sunshine Coast University Hospital, Birtinya, Qld, Australia

Mitotic count is a semiquantitative part of the routine histological grading of breast cancers and introduces significant interobserver reliability issues. One potential systematic solution is artificial intelligence (AI) and computer vision algorithms. Previous literature has shown proprietary AI models to be effective at counting breast cancer mitoses. ${ }^{1}$

Aim: To evaluate the efficacy of training a deep learning computer vision model using only opensource software, to improve the democratisation of $\mathrm{AI}$ in this application. 